\title{
Barriers in the management of childhood asthma: what care giver thinks about long term controller medication?
}

\author{
Abbas J. ${ }^{1}$, Pandey D.C. ${ }^{2}$, Verma A. ${ }^{3}$, Siddiqui S. ${ }^{4}$ \\ ${ }^{1}$ Dr. Jaigam, Abbas, Associate Professor, ${ }^{2}$ Dr. Dinesh Chandra Pandey, Associate Professor, ${ }^{3}$ Dr. Ashish, Verma \\ ,Assistant Professor, ${ }^{4}$ Dr. Samshul, Hoda Siddiqui, Senior Resident, all authors are affiliated with Department of \\ Pediatrics, CIMSH, Lucknow, India
}

Address for Correspondence: Dr. Dinesh Chandra Pandey, E3499/1 Rajajipuram, Lucknow, India. E-mail: dr_dc_pandey@yahoo.com

\begin{abstract}
s
Introduction: Asthma is the most common, chronic lower respiratory disease in childhood.Despite of the several guidelines and/or consensus documents available to support medical decisions to paediatric asthma; there are little updates available on the barriers' to childhood asthma care among communities. Objectives: We aimed to determine social barriers to the management of childhood asthma. Methods: This was a qualitative, cross-sectional hospital based study in children aged between 1-15 years. Results: total 423 children with asthma were recruited from July 2014 to July 2016.out of them 126(29.78\%) had mild intermittent, 190(44.91\%) had mild persistent, 73(17.25\%) had moderate persistent and 32(7.56\%) had severe persistent asthma. In all persistent asthma cases long term controller medication was prescribed in which only $186(62.62 \%)$ accepted long term controller, while 111(37.37\%) patients did not. Reasons fornon-acceptance of long term controller medication in new cases were of financial constraints $25(22.52 \%)$, fear of dependency of controller medication 23(20.72\%), fear ofside effect 17(15.31\%), social stigma of inhalational device 15(13.51\%), more preference to cough syrup 31(27.97\%).Conclusion: A large numbers of barriers existed in the management of childhood asthma which has a bad impact on the patients and their families.
\end{abstract}

Keywords: Paediatric Asthma, Barriers, Management, Controller Medication

\section{Introduction}

Asthma is the most common chronic condition among children under the age of 18 , affecting 6.3 million [1]. Asthma most often starts early in life and has variable clinical courses, which may progress or remit over time.It is more prevalent in children with a family history of atopy, symptoms and exacerbations are frequently provoked by a wide range of triggers including viral infections, indoor and outdoor allergens, exercise, tobacco smoke and poor air quality. The prevalence of childhood asthma has grown dramatically in most western countries of the world [2-4]. Various studies from India have been reported, prevalence ranging from $3.5 \%$ up to $29.5 \%$ [5]. Childhood asthma presents as a substantial burden to the

Manuscript received: $10^{\text {th }}$ September 2017

Reviewed: $17^{\text {th }}$ September 2017

Author Corrected: $23^{\text {rd }}$ September 2017

Accepted for Publication: $30^{\text {th }}$ September 2017 patient, their family and society. High frequencies of sleep disturbances due to asthma (up to 34\%), absence from school (23-51\%) and limitation of activities (47\%) have been reported [6-8].

Pharmacotherapy for childhood asthma has been described in general asthma guidelines, including the recently updated Global Initiative for Asthma (GINA) guidelines [9]. Despite of the international consensus on management of Asthma in childhood, many barriers exist, which may alter the course of the disease and adversely affect quality of life of the caregivers and their families.

So, in established disease, control can be achieved and maintained only with appropriate treatment, education, and monitoring, as well as removal of barriers in most of the children. 


\section{Methods}

This was a cross-sectional hospital based study in which caregivers of asthmatic children aged 1-15 yearsattending paediatric out door department in Career Institute of Medical Sciences Lucknow, India aged were administered a self-designed questionnaire in the academic years July'2014July'2016.

Sampling methods and sample collection- There were 423 participants enrolled in the study that have been diagnosed with asthma. Prior permission from the caregivers was taken. The study was approved by the local independent ethics committee.
The caregivers of asthmatic children were administered a self-designed questionnaire. Studyfollowed GINA guideline 2002 to classify severity. All persistent asthma cases were followed and data analysed at six months follow up.

Exclusion and inclusion criteria- Study included all patients aged 1-15years diagnosed with bronchial asthma as per GINA guideline 2002 . Study excluded patients with congenital malformation, genetic defects, and chronic neurological disorder with feeding difficulty

Statistical analysis- Data were analysed using SPSS statistical software version 20.mean and SD were calculated for categorical variable.

\section{Results}

Table-1: Baseline demographic and clinical characteristics of patients with childhood asthma $(\mathrm{N}=423)$

\begin{tabular}{|c|c|}
\hline Characteristics & N (\%) \\
\hline Male & $252(59.57 \%)$ \\
\hline female & $171(42.42 \%)$ \\
\hline $\mathrm{Wt}(\mathrm{kg})($ mean $\pm \mathrm{SD})$ & $19.36 \pm 11.43$ \\
\hline $\mathrm{Ht}(\mathrm{cm})($ mean $\pm \mathrm{SD})$ & $102.26 \pm 2.76$ \\
\hline \multicolumn{2}{|l|}{ Socioeconomic Status } \\
\hline Upper & $275(65 \%)$ \\
\hline Lower & $126(34.98 \%)$ \\
\hline Urban & $314(74.23 \%)$ \\
\hline Rural & $109(25.76 \%)$ \\
\hline \multicolumn{2}{|l|}{ Asthma Severity } \\
\hline Mild intermittent & $126(29.78 \%)$ \\
\hline Mild persistent & $190(44.91 \%)$ \\
\hline Moderate persistent & $73(17.25 \%)$ \\
\hline Severe persistent & $32(7.56 \%)$ \\
\hline Well controlled & $81(19.14 \%)$ \\
\hline Not well controlled & $211(49.88 \%)$ \\
\hline Poorly controlled & $131(30.96 \%)$ \\
\hline \multicolumn{2}{|l|}{ Prior Use Of Long Term Controller } \\
\hline Never Received & $233(55 \%)$ \\
\hline $\begin{array}{l}\text { Received but stoppedduration of use(months) mean } \\
\qquad \pm \mathrm{SD}(2.66 \pm 1.48)\end{array}$ & $147(34.75 \%)$ \\
\hline $\begin{array}{l}\text { Oncontroller medication duration of use(months) mean } \\
\qquad \pm \mathrm{SD}(9.5 \pm 5.5)\end{array}$ & $43(10.16 \%)$ \\
\hline Counselled for long term controller at CIMS \& H (all persistent asthma cases) & $297(70.21 \%)$ \\
\hline Did notaccept & $111(37.37 \%)$ \\
\hline Accepted & $186(62.62 \%)$ \\
\hline
\end{tabular}


Patients characteristics- This study conducted among 423 children diagnosed with bronchial asthma attending the pediatric outpatient department of Career Institute of Medical Sciences Lucknow between July' 2014 and July' 2016. Out of them, 252(59.57\%) were male and 171(40.42\%) were female. Amongst 423 children with asthma, 126(29.78\%) had mild intermittent, 190(44.91\%) had mild persistent, 73(17.2\%) had moderate persistent, and $32(7.56 \%)$ had severe persistent asthma.

Out of 423 children 233(55\%) never received controller medication, 147(34\%) received but stopped after few months (mean $\pm \mathrm{SD},(1.62 \pm 0.74)$ and $43(10.16 \%)$ were on regular controller medication. Asthma was controlled in $81(19.14 \%)$, not well controlled in $211(49.88 \%)$, poorly controlled in 131(30.96\%). All persistent asthma cases $(70.21 \%)$ were counselled for controller medication; only $62.62 \%$ had accepted controller medication, while $37.37 \%$ did not accepted.

Barriers to long term controller in new cases- Table 2 depicts barriers for long term controller medication in new cases in which controller was counselled were of financial constraints $25(22.52 \%)$, fear of dependency of controller medication $23(20.72 \%)$, fear of side effect $17(15.31 \%)$, social stigma of inhalational device $15(13.51 \%)$, more preference to cough syrup 31(27.92\%).

Table-2: Barriers responsible for non-acceptance of controller medication new cases(N=111)

\begin{tabular}{|c|c|}
\hline Barriers & N (\%) \\
\hline Fear of dependency of controller medication & $23(20.72 \%)$ \\
\hline Financial constraints & $25(22.52 \%)$ \\
\hline Fear of side effects & $17(15.31 \%)$ \\
\hline Social stigma of inhalational device & $15(13.51 \%)$ \\
\hline More preferenceoral medicine & $31(27.92 \%)$ \\
\hline
\end{tabular}

Table-3: Characteristics of persistent childhood asthma, followed at six months $(\mathrm{N}=165)$

\begin{tabular}{|c|c|}
\hline Characteristics & N (\%) \\
\hline Stopped controller medication & $71(43 \%)$ \\
\hline Duration of use(months) (Mean \pm SD) & $1.62 \pm 0.74$ \\
\hline Lost follow up & $27(16.36 \%)$ \\
\hline Continued controller medication at six months & $67(40.60 \%)$ \\
\hline Good compliance & $18(26.86 \%)$ \\
\hline Poor compliance & $49(73.13 \%)$ \\
\hline Level of Control & $31(22.46 \%)$ \\
\hline Controlled & $42(30.43 \%)$ \\
\hline Not well controlled & $65(47.10 \%)$ \\
\hline Poorly controlled &
\end{tabular}

Barriers to long term controller in follow-up cases- Study followed upon children with persistent asthma in which controller was given and follow up data were obtained at six months. Table no 4 depicts barriers to controller medication in follow up cases.Out of 165 follow-up children who were on controller, 27(16.36\%) were lost follow up, 71(43\%) stopped controller medication after 1 or more follow up (duration of use (months), (mean $\pm \mathrm{SD}, 1.62 \pm 0.74$ ) and $67(40.60 \%$ ) had continued controller.

Out of 67, who continued controller medication, $18(26.86 \%)$ had good compliance and 49(73.13\%) had poor compliance.Reasons for cessation of controller medication were of short term improvement 13(18.18\%), financial constraints $10(14.84) \%$, summer season $8(11.26 \%)$,social stigma of inhalational device 7 ( $9.85 \%)$, fear of addiction of controller drugs 7 ( 9.85\%) and fear of side effects $6(8.45 \%)$, use of alternative therapy(homeopathy and Ayurveda) 6(8.45\%) and 14(19.71\%) preferred oral medicine overinhaled controller. 
Table-4: Barriers responsible for stoppage of the controller medication in persistent asthma, followed at six months $(\mathbf{N}=71)$

\begin{tabular}{|c|c|}
\hline Barriers & N (\%) \\
\hline Short term improvement & $13(18.18 \%)$ \\
\hline Fear of side effects & $6(8.45 \%)$ \\
\hline Financial constraints & $10(14.84 \%)$ \\
\hline Social stigma of inhalational device & $7(9.85 \%)$ \\
\hline Fear of addiction of controller & $7(9.85 \%)$ \\
\hline Use of alternative therapy including homeopathy and Ayurveda & $6(8.45 \%)$ \\
\hline Summer season & $8(11.26 \%)$ \\
\hline More preference to oral medication & $14(19.71 \%)$ \\
\hline
\end{tabular}

\section{Discussion}

Outcome of management of chronic diseases especially, Bronchial asthma depends on how effectively the treatment guideline is implemented at the community level. A large gap exists between the latest treatment guidelines for many chronic diseases and the translation of these recommendations into everyday patient care [10$11]$.Study from India by SS Salvi reported that only $36 \%$ of asthmatic children used controller [12].In our study, we assessed barriers responsible for poor acceptability of controller medication in persistent asthma cases.

The financial constraints were reported in new and follow up cases as $22.52 \%$ and $14.84 \%$ respectively. Study by A Lal et al reported, severe economic burden was experienced by the family in $25.9 \%$ cases [13]. In persistent cases in which controller has been prescribed, $43 \%$ patients had stopped therapy and $16.30 \%$ patients had lost follow-up and $40 \%$ cases continued controller at six months follow up. Amy H.Y. Chan et al reported adherence of prescribed controller medication was $30 \%$ [14]. In present study $31.3 \%$ in new cases \& $15.3 \%$ in follow up cases did not accept controller due to social stigma of inhalation devices.Study by GaudeGajanan et al reported, $24.6 \%$ stigmatization of inhalation therapy in asthma management [15].

In our study in new cases out of all persistent, $23(20.72 \%)$ refused to accept controller medication due to fearof addiction and 17 (15.31\%)refused to accept due to fear of side effects while in follow up cases $7(9.85 \%)$ stopped controller due tofear of addiction , and $6(8.45 \%)$ stopped controller due to fear of side effects the study of Al- Jahdali et al raises the importance of the education program of the patient involved in asthma care to discuss with them the role of asthma medications, particularly ICS, and to correct common fears and misconceptions. Among the most common fears hindering regular ICS use was their potential to lead to addiction (60\%) and worry from steroid side effects $41 \%$ [16].Our finding that $8(11.26 \%$ ) follow up cases stopped controller medication in summer while finding of Cecil Vella et al reported $23 \%$ care giver stopped controller medication in summer season [17].In our study 31(27.97\%) in new cases and $14(19.71 \%)$ in follow-up cases, care giver of asthmatic children denied long term controlleras they preferredshort term oral medication especially cough syrupoverlong term inhalation therapy.

Study by RolaZaraket et al reported that $67 \%$ of parents preferred oral route over inhalational route [18].

According to guidelines, all such patients should take regular preventive therapy [19]. Thus; gross under-treatment appears to be a basic problem in management of asthma. Undertreated patients may develop permanent occlusive changes in the airways [20, 21].

The NAEPP Guidelines have emphasized the need for a partnership between clinician) and patient to improve treatment adherence and disease outcome [22].

\section{Conclusion}

There were large numbers of barriers existed in the management of childhood asthma which has a bad impact on the patients and their families. On the basis of findings of our study we recommend 
1. More awareness and education of parents are neededto remove myths related to inhalational devices in childhood asthma management.

2. More awareness of general physicians about childhood asthma management is needed, as they are covering bulk of patients in developing countries.

3. There should be restriction onsaleof over the counter cough syrup by pharmacist.

4. There should be free availability of controller and rescuer medication in government hospital, as financial constraints is a one of the major obstacle in delivering health services to underprivileged population.

What this study add?Findings of present study can be used to inform and enhance the knowledge of the caregivers of asthmatic children in the management to remove barriers which may directly affect the prevalence as well as the positive outcome.

\section{Contribution}

- Dr.Jaigam Abbas-design of work and data collection

- Dr.Dinesh Chandra Pandey-data analysis and interpretation

- Dr.Ashish Verma -maintenance of records and drafting of article

- Dr.Samshul Huda Siddiqui- critical revision of article

Funding: Nil, Conflict of interest: None initiated, Perission from IRB: Yes

\section{References}

1. Asthma in Children Fact Sheet, American Lung Association, 2004.

2. Pearce N, Aït-Khaled N, Beasley R, Mallol J, Keil U, Mitchell E et al.; ISAAC Phase Three Study Group. Worldwide trends in the prevalence of asthma symptoms: phase III of the International Study of Asthma and Allergies in Childhood (ISAAC). Thorax. 2007 Sep;62(9):75866. https://doi.org/10.1136/thx.2006.070169PMID: 17504817

3. Anderson HR, Gupta R, Strachan DP, Limb ES. 50 years of asthma: UK trends from 1955 to 2004. Thorax. 2007 Jan;62(1):85-90.
4. Toelle BG, $\mathrm{Ng} \mathrm{K}$, Belousova E, Salome CM, Peat JK, Marks GB. Prevalence of asthma and allergy in schoolchildren in Belmont, Australia: three cross sectional surveys over 20 years. BMJ. 2004 Feb;328(7436):386-

7. https://doi.org/10.1136/bmj.328.7436.386.

5. Chhabra SK, Gupta CK, Chhabra P, Rajpal S. Prevalence of bronchial asthma in school children in Delhi. J Asthma. 1998;35(3):291-6.

6. Fuhlbrigge AL, Guilbert T, Spahn J, Peden D, Davis K. The influence of variation in type and pattern of symptoms on assessment in pediatric asthma.Pediatrics. $2006 \quad$ Aug;118(2):61925. https://doi.org/10.1542/peds.2005-2963.

7. Gustafsson PM, Watson L, Davis KJ, Rabe KF. Poor asthma control in children: evidence from epidemiological surveys and implications for clinical practice. Int J ClinPract. 2006 Mar;60(3):321-34. https://doi.org/10.1111/j.13685031.2006.00798.x .

8. Wildhaber J, Carroll WD, Brand PL. Global impact of asthma on children and adolescents' daily lives: the room to breathe survey. PediatrPulmonol. $2012 \quad$ Apr;47(4):34657. https://doi.org/10.1002/ppul.21557.

9. Global Strategy for Asthma Management and Prevention. 2006. "The Global Initiative for Asthma

2006".http://www.ginasthma.com/GuidelinesResou rces.aspaccessed 7 November 2007

10. Shahady EJ. Letter to the editor on performance gap. JAMA. 2001;286:1834..

11. Crossing the Quality Chasm: A New Health System for the 21st Century.Institute of Medicine (US) Committee on Quality of Health Care in America. Washington (DC): National Academies Press (US); 2001.

12. Salvi SS, Apte KK, Dhar R, Shetty $\mathrm{P}$, Faruqi RA, Thompson PJ, Guleria R.AsthmaInsights and Management in India: LessonsLearnt from the AsiaPacific AsthmaInsights and Management (AP-AIM) Study. J Assoc Physicians India.2015 Sep;63(9):36-43. 
13. Lal A, Kumar L, Malhotra S. Socio-economic burden of childhood asthma. Indian Pediatr. 1994 Apr;31(4):425-32. .

14. Amy H.Y. Chan, Alistair W. Stewart, Juliet M. Foster, Edwin A. Mitchell, Carlos A. Camargo Jr, Jeff Harrison "Factors associated with medication adherence in school-aged children with asthma" ER J open research 2016 2: 000872015 ; DOI: https://doi.org/10.1183/23120541.000872015.

15. Gajanan G, Padbidri VS, Chaudhury A. VinaySandeepPadbidri, Alisha Chaudhury "Assessment of Knowledge and Attitude of Parents Towards the Allergy and Bronchial Asthma in Their Children". Int J Med Public Health. 2016;6(3):121-

5. https://doi.org/10.5530/ijmedph.2016.3.5.

16. Al-Jahdali HH, Al-Zahrani AI, Al-Otaibi ST, Hassan IS, Al-Moamary MS, Al-Duhaim AS et al. Perception of the role of inhaled corticosteroids and factors affecting compliance among asthmatic adult patients. Saudi Med J. 2007 Apr;28(4):569-73.

17. Vella C. GianlucaBezzina, Matthew Urpani "An audit of compliance of inhaled steroid medication in Maltese asthmatic children."A comparison between 2008 and 2014. Malta Med J. 2014;26(02):25-28

18. Zaraket R, Al-Tannir MA, Bin Abdulhak AA, Shatila A, Lababidi H. Parental perceptions and beliefs about childhood asthma: a cross-sectional study. Croat Med J. 2011 Oct;52(5):63743. https://doi.org/10.3325/cmj.2011.52.637.

19. Global Initiative for asthma. Asthma management and prevention. NIH publication 1995; 96-3659A:19

20. Ulrik CS, Backer V, Dirksen A. A 10 year follow up of 180 adults with bronchial asthma: factors important for the decline in lung function. Thorax. 1992 Jan;47(1):14-8. https://doi.org/ 10. 1136 /thx. 47.1.14 PMID: 1539138

21. Djukanovic R. Airway remodelling: what is it? Asthma J. 1997;2:130-33.

22. NAEPP. National Asthma Education and Prevention Program. Expert Panel Report 2. Clinical Practice Guidelines: Guidelines for the Diagnosis and Management of Asthma. National Institutes of Health; National Heart, Lung, and Blood Institute. NIH Publication No. 98-4051; July 1997.

\section{How to cite this article?}

Abbas J., Pandey D.C., Verma A., Siddiqui S. Barriers in the management of childhood asthma: what care giver thinks about long term controller medication?. J PediatrRes. 2017;4(09):566-571.doi:10. 17511/ijpr.2017.i09.05. 